\title{
Rubeola Antigen Measurement
}

National Cancer Institute

\section{Source}

National Cancer Institute. Rubeola Antigen Measurement. NCI Thesaurus. Code C154815.

The determination of the Rubeola antigen present in a sample. 